\title{
Summary: Addressing the Interactional Challenges of Moving Collaborative Adaptive Management From Theory to Practice
}

\author{
Kathi K. Beratan ${ }^{1}$
}

\begin{abstract}
Translating the attractive concept of collaborative adaptive management (CAM) into practice has proven very difficult. The papers included in this Special Feature explore why this is true and suggest how the challenges might be addressed. This summary highlights common themes, major challenges, and implications for research and practice. Many of the included papers emphasize the central importance of collaboration and stakeholder engagement as a response to complexity and uncertainty. Collectively, the papers make the case that a lack of knowledge about how to manage the human dynamics of comanagement poses a major challenge to implementing CAM. Human activities are the primary drivers of system change in most natural resource management systems, so attention to human dynamics is essential for developing useful change hypotheses and leading indicators that can provide useful and timely feedback for adaptive management. Institutions need to evolve to support adaptive and collaborative management processes. This will require thoughtful design of CAM processes, along with commitment of sufficient time and resources. Implementation challenges should be considered as a major focus for research rather than as simply barriers to progress. More effective ways of capturing practitioners' experiential knowledge are required to improve the practice of CAM. This Special Feature suggests that the concept of a CAM practitioners' journal has promise, but realization of that promise will require careful attention to the needs of and constraints on practitioners.
\end{abstract}

Key Words: collaborative adaptive management; institutional change; leading indicators; process design; stakeholder participation

\section{INTRODUCTION}

The topic of this Special Feature is exploring opportunities for advancing collaborative adaptive management (CAM) through integrating researcher and practitioner experiences. Many CAM projects have progressed to a point where preliminary impacts can be assessed. The Core Advisory Group of the Collaborative Adaptive Management Network (CAMNet) has recognized that many of the most interesting and valuable insights gained from these projects came from the experiential knowledge of practitioners who had to work through the considerable implementational challenges. In response to this identified need to capture and disseminate practitioners' insights to improve the effectiveness of CAM in practice, CAMNet is considering development of a new journal aimed at CAM practitioners (Galat and Berkley 2014).

For an individual's experiential knowledge to usefully inform general practice, it must be documented and disseminated in a form that is accessible to practitioners and useable in practice. Such communications can also inform further theory development and subsequent evolution of practice. Among other goals, this Special Feature was intended to be a test of the journal format as a channel for practitioner communication; thus, it represents an experiment very much in the spirit of adaptive management.

\section{CONTEXT: MANAGING COMPLEXITY}

Most natural resource management projects fall within the realm of "wicked problems." Such problems are difficult to address because there are multiple ways of defining the nature of the problem, there are multiple and potentially conflicting criteria for defining solutions, what constitutes a solution for some people can be viewed as a problem for other people with different priorities, and there are no clear criteria for determining when the problems are solved (Rittel and Weber 1973). These challenges reflect the origin of such problems as the emergent and contingent products of many complexly interlinked cultural, ecological, and economic phenomena in social-ecological systems. As a consequence of these complex dynamics, it is effectively impossible to precisely predict the outcomes of management actions (Holling et al. 2002).

CAM developed as a means of dealing with complexity, interconnectedness, uncertainty, and change. It combines two different approaches to decision making: adaptive management (AM) and collaboration (Childs et al. 2013, Scarlett 2013). AM is a structured management approach that treats management actions as experiments, monitoring results and incorporating the findings into future management actions (LoSchiavo et al. 2013, Monroe et al. 2013). AM acknowledges that managed resources will always change as a result of human intervention, that surprises are inevitable, and that new uncertainties will emerge (Gunderson 1999). AM efforts have tended to focus on enhancing scientific knowledge of the biophysical elements of the system being managed, with success limited by insufficient linkage of that knowledge to management (Scarlett 2013). Collaborative approaches seek to improve outcomes by inclusion of multiple governmental and nongovernmental stakeholders in decision processes (Conley and Moote 2003). CAM seeks to integrate the scientific and process elements of natural resource management by combining the learning and experimental aspects of AM with the participatory and linking features of collaborative management to more effectively deal with complex problems (Monroe et al. 2013, Smedstad and Gosnell 2013).

Approaches to natural resource management and other change processes fall along a continuum from command-and-control to true CAM (Fig. 1). The approach chosen for a given management situation depends on the particulars of that situation, and CAM is not appropriate for all situations (Caves et al. 2013, Greig et al. 
2013). An approach on the CAM end of the continuum is almost certain to be needed in situations where transformative rather than incremental change is the goal. However, CAM processes will be of limited value in situations involving rigid legal and regulatory requirements and organizational cultures (Childs et al. 2013, LoSchiavo et al. 2013, Scarlett 2013). When collaboration is used poorly or inappropriately, it can create more problems than it solves (Imperial and Hennessey 2000). A failed process is costly in terms of time and effort, and in social capital consumed rather than built (Conley and Moote 2003).

Fig. 1. Natural resource management approaches fall along a continuum defined by the level of collaboration and stakeholder engagement required to effectively address the complexity and uncertainty of a particular problem situation.

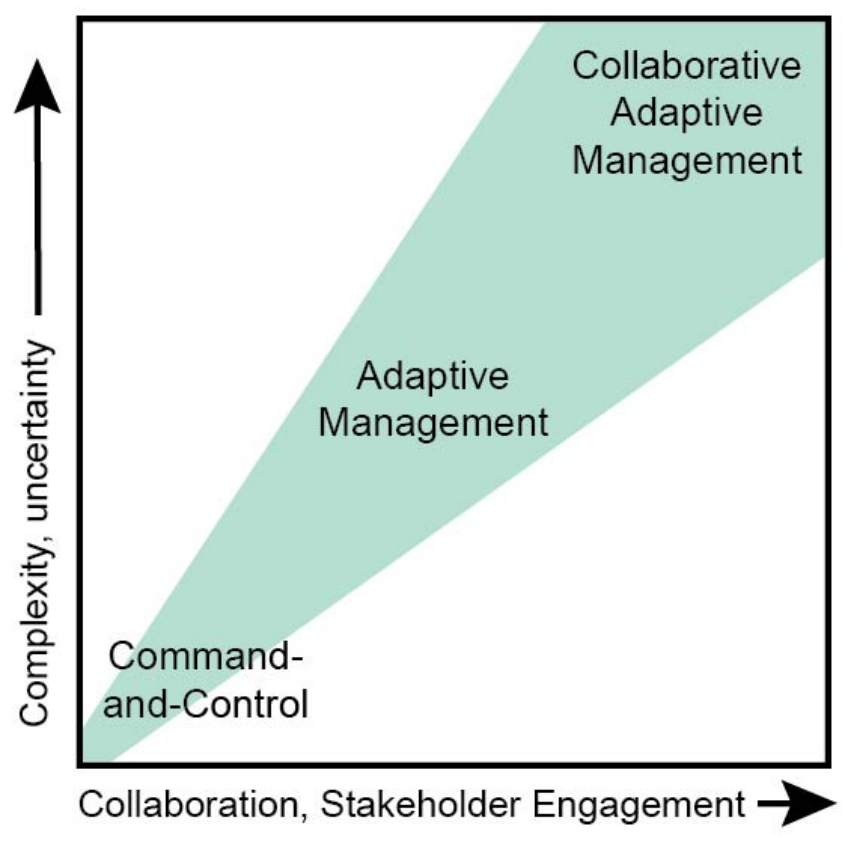

\section{COMMON THEMES IN THIS SPECIAL FEATURE}

\section{Stakeholder participation}

Many contributions to this Special Feature emphasize the central importance of collaboration and stakeholder engagement as a response to complexity and uncertainty.

- Reflecting on her experiences as Deputy Secretary and Chief Operating Officer at the U.S. Department of the Interior, Scarlett (2013) points to CAM's position at the intersection of science and decision making. The fact that resource management questions affect people and involve trade-offs among competing goals and interests highlights the importance of participatory democracy and collaboration, and emphasizes the fundamental question of what the respective roles are for scientists, technical experts, and the public.
- Based on study of a CAM project centered on grazing lands in Arizona, Childs and colleagues (2013) emphasize that adaptive social processes are critical to the success of CAM. They note that mandated collaboration is unlikely to foster necessary trust and emphasize the value of professional facilitation for helping teams set up place-specific processes and management structures that can encourage meaningful engagement.

- Assessment of AM projects in the forest sector lead Greig and colleagues (2013) to conclude that enabling AM requires working with people to appreciate their concerns, develop a common understanding, and produce an environment of trust.

- Comparative analysis of multistakeholder working groups in northern Florida suggested to Monroe and colleagues (2013) that intermediate steps focused on social learning and acquiring experience can overcome commonly cited barriers to CAM by building knowledge, confidence, and capacity among stakeholders.

- Smedstad and Gosnell (2013) looked at government-led CAM of riparian resources in the western United States and concluded that outside interventions have only limited potential for catalyzing the self-organization of new or modified governance arrangements capable of supporting cross-scale networks and ongoing cycles of learning from actions. They suggest that a larger scale approach may be more likely to result in enduring change.

Collectively, the papers in this Special Feature make the case that lack of knowledge about how to manage the human dynamics of comanagement poses a major challenge to implementing CAM. The site specificity of environmental and natural resource management problems means that there is no one-size-fits-all prescription or blueprint (Green et al. 2013). No CAM process starts from scratch with a clean slate; each builds on a history of events and interactions. Thus, the starting point for implementing CAM depends on antecedent conditions, context, and situational factors (Monroe et al. 2013, Smedstad and Gosnell 2013), which drive the dynamics of emergence in the system of interest. The historical context that shaped the relationships among key actors is particularly important (Greig et al. 2013). Social factors, tied to social learning and the development and deployment of social capital through increased stakeholder involvement, are essential elements of CAM (Benson and Stone 2013, Childs et al. 2013, Smedstad and Gosnell 2013, Curtin 2014).

The inclusion of stakeholders is a defining characteristic of CAM. Involving stakeholders in the decision process is supposed to build trust and establish legitimacy, thereby decreasing transaction costs and delays (Berkley 2013, Scarlett 2013). Successful implementation of management plans is considered unlikely without stakeholder buy-in (Green et al. 2013). In addition, stakeholder involvement provides critical flows of experiential knowledge and the articulation of multiple values (Scarlett 2013) 
that can yield a wider range of alternatives (Benson and Stone 2013) and highlight important uncertainties (Loftin 2014).

The inclusion of stakeholders is also the source of most of the barriers to implementation of CAM projects (Monroe et al. 2013). Jurisdictions have different priorities, and elected officials and professional staff must be responsive to local residents. Different agencies within a jurisdiction have different responsibilities and may have little flexibility in what they do and how they do it. Adding stakeholders to the mix increases the difficulty, and meaningful inclusion of stakeholder groups is rarely achieved although frequently attempted. Meaningful stakeholder participation requires a two-way flow of information, with stakeholder input actually influencing the final decision (Green et al. 2013, Laws et al. 2014). Resource managers typically lack governing mechanisms supportive of this level of stakeholder engagement (Scarlett 2013).

The way in which a CAM process is initiated is a critical determinant of the ultimate success or failure of that process. Stakeholder participation is especially important, yet commonly lacking, in the early stages of a CAM process (Greig et al. 2013). A particularly challenging characteristic of wicked problems is that the definition of the problem is contestable. Everyone views things differently, and the very things that some stakeholders consider to be problematic may be seen as beneficial by other stakeholders (Loftin 2014). As Greig and colleagues (2013) emphasize, the problem definition used to frame an adaptive management initiative will establish the focus for subsequent work, so it is important to invest in getting it right. Because stakeholders need to be engaged in management efforts, their meaningful input is needed to develop problem definitions that can contribute toward moving forward rather than setting the stage for confrontation.

\section{Institutional barriers}

Several papers explore the role played by both formal and informal institutional barriers in hindering implementation of CAM projects.

- Benson and Stone (2013) found that practitioners associated with CAMNet reported institutional barriers to and constraints on CAM efforts, including limitations on flexibility stemming from legal requirements.

- Based on lessons learned from implementation of the Comprehensive Everglades Restoration Project, LoSchiavo and colleagues (2013) emphasize that governance structure and process elements need to be included in the design of CAM to facilitate effective feedback between hypothesisbased management activities and monitoring and assessment efforts, and to promote integration of the approach into established practice.

- Synthesizing lessons learned as a practitioner, Loftin (2014) points out that the challenges faced by CAM projects are not limited to the scientific arena, but relate to all aspects of project design and management. The level of organizational commitment needs to match the scale of the problems being addressed, and success of CAM projects should be measured in terms of achieving the desired project performance and not just in terms of completing project activities on time and on budget.

- Laws and colleagues (2014) emphasize that conflict is inherent in natural resource management. They suggest that good institutional design can permit well-managed conflict to contribute to the effective management of natural resources in complex and changing circumstances.

- Green and colleagues (2013) suggest that resilience principles can inform design of treaties and adaptive governance institutions that can deal with variability and uncertainty. Of particular importance is the need for broad collaboration both among a range of stakeholders and among institutions with authority to act at different scales or on different system aspects.

All resource management regimes are embedded in a wider institutional context, and both formal and informal institutions are a key link between social systems and ecosystems (DavidsonHunt and Berkes 2002, Carlsson and Berkes 2005). For long-term transformation of governance arrangements, CAM processes must become embedded within governance institutions (Smedstad and Gosnell 2013). Current institutions are not designed to carry out CAM, having limited capacity for flexibility and power sharing, and many key actors have organizational cultures that have little tolerance for uncertainty and error (Benson and Stone 2013, Childs et al. 2013, Greig et al. 2013, LoSchiavo et al. 2013). Resource managers often lack mechanisms to include meaningful stakeholder participation in decision processes (Scarlett 2013), as well as institutional support for experimentation that does not produce results quickly (Benson and Stone 2013). There is a need for institutional evolution toward adaptive and collaborative management processes, ones that "allow managers the opportunity to be wrong" (Loftin 2014).

\section{Design of the management process}

Most of the papers in this Special Feature emphasize that careful design of the management process is critical to the success of a CAM project. An important assumption at the heart of CAM is that the outcomes of adaptive management efforts are strongly influenced by interactional dynamics among the many relevant agencies, organizations, and key stakeholders associated with a given management situation. This suggests that outcomes can be improved if the people setting up a CAM process, the process designers, pay careful attention to interactional dynamics when planning.

- Pratt Miles (2013) emphasizes that process designers need to take into account practical considerations when choosing among different collaborative mechanisms, including (1) the resources that will be required and (2) the time needed to establish the group and determine who will make decisions and how decisions will be made. Putting a collaborative process in place does not mean that there will not be conflicts, only that there will be a process in place for addressing conflicts as they arise. 
- Margoluis et al. (2013) note that project design tools used in other fields have great potential to enhance the design of CAM projects. In particular, they suggest that results chains (1) can assist with specification of the theory of change upon which the action plan is based and (2) can help assess whether the best interventions have been selected, are being well implemented, and are achieving the desired impacts.

- Because stakeholder support is critical for AM efforts to implement management actions, Berkley (2013) suggests that subjective monitoring and assessment of stakeholderrelevant processes, systems, and relationships needs to be included in the design of AM projects.

- Curtin (2014) recommends resilience-focused process design that includes both a vision statement with clear broad goals and a detailed set of principles to make sure that the project or organization holds true to its founding ideals. He suggests that these can provide a framework that both maintains the collaborative organization and allows it to take advantage of opportunities when they arise.

- Caves and colleagues (2013) conclude that CAM practices need to be modified to enable flexible responses to uncontrollable and unpredictable change; possible modifications include inclusion of nested resource objectives and scenario planning.

Information exchange, which is at the heart of collaboration, requires trust-based relationships (Jackson and Stainsby 2000). Trust-based relationships are not yet in place in most problem situations, and it may be difficult to persuade key stakeholders to participate because participation requires ceding some control, sharing risks, and becoming dependent on others for success (Himmelman 1996). Therefore, relationship building should be a central focus of process planning (Pratt Miles 2013), and efforts aimed at enhancing the collaborative capacity of key actors through social learning may be a necessary precursor to CAM (Monroe et al. 2013).

An effective CAM process takes time (Margoluis et al 2013, Curtin 2014, Loftin 2014). Process design needs to take into account the commonly overlooked fact that participation is a scarce resource (Andrews 2002); a truly collaborative process will develop only if the process conveners demonstrate respect for and appreciation of the participants' time (Beratan and Karl 2012). Beierle and Konisky (2000) found that success in public participation efforts was highly related to the lead agency's commitment to the participatory process, as demonstrated by provision of adequate funding and staffing, lack of turnover, and sustained interest in the process. Every interaction is a learning experience for everyone involved; among the most important things participants learn from interactions with process leaders is whether or not it is worth the time and effort to participate!

The design and conduct of meetings can have a big impact on the relationships and motivations of participants (Childs et al. 2013). Several papers in this Special Feature emphasize the value of having meetings set up and run by a neutral facilitator, someone who is accepted by participants as nonpartisan and who can help make meetings a "safe space" for dialogue and social learning (Caves et al. 2013, Childs et al. 2013, Laws et al. 2014). Good facilitators help participants plan how they will handle disputes because conflict is inherent in CAM processes (Laws et al. 2014), but the negative impacts of conflict can be lessened if the process design includes agreed-on methods of dispute resolution (Green et al. 2013). Care must be taken in choosing appropriate facilitators; facilitation is a special area of expertise with particular skill sets, so training and experience matter. All of the participants need to feel comfortable with the facilitator(s) and therefore should have some say in the selection process.

\section{Monitoring and evaluation}

Almost all of the papers in this Special Feature stress monitoring and evaluation as critical to CAM. Loftin (2014) notes that there are two types of project failures: failure to be implemented and failure to perform as intended after implementation. Therefore, monitoring of both the management process and project impacts is needed. It is also important to consider who will be using the information and what they will be using it for when deciding what data to collect, how to analyze them, and how to present them. To be useful, indicators need to link findings to actual decision options faced by decision makers and managers (Scarlett 2013). Because stakeholders are critical to design and implementation of a CAM process, they need to be engaged in indicator selection so that things they perceive as relevant are included (Berkley 2013). Resources available for monitoring are limited, and care must be taken to spend those resources strategically (Caves et al. 2013).

A serious challenge for monitoring programs is that useful information is needed quickly if trends and problems are to be detected early enough to permit adjustment of management plans (Pratt Miles 2013, Scarlett 2013). Unfortunately, by the time changes in the condition of the resource being managed are detectable, it is likely to be too late to act. Another factor that interferes with the feedback loop is the difference in time scale between the critical processes in the system being managed and in the management system; natural resources that are the focus of management actions generally experience change on time scales that are very long relative to political and organizational cycles. Management cannot be adaptive unless relevant changes can be identified and assessed soon enough to influence implementation of management plans (Green et al. 2013).

\section{DISCUSSION}

A starting point for all of the papers is that it has proven extremely difficult to translate the very attractive concept of CAM into practice. Each paper looks at why implementation has been so difficult and what we can learn from pioneering attempts. Collectively, the papers support the concept that broad stakeholder engagement is the single most important determinant of success in a CAM process. A previous Special Feature in this journal likewise noted that many attempts at sustainable resource governance have failed because of inadequate attention to the role of social relationships in shaping environmental outcomes (Crona and Hubacek 2010).

Stakeholder involvement is important for more than just helping to gain acceptance of science-based management plans; it is 
critical for gathering sufficient knowledge of a system to permit development of practical and effective management plans. Human activities are the primary drivers of system change in most management situations, so knowledge about the system's human dynamics, the social part of a social-ecological system, is essential for predicting the likely outcomes of management actions. In fact, social knowledge can be more important for accurate prediction of outcomes than scientific findings regarding biophysical processes. The people with the deepest understanding of a social system are those who live and work within that system, so inadequate stakeholder engagement will result in an incomplete understanding of the system and inaccurate causal hypotheses. Each individual has experience with only a small part of the system, so the collective knowledge of a diverse group of people is needed to gain a reasonably complete picture of the problemrelevant components and dynamics of the whole system (Beratan 2007).

Attention to human/social systems is also critical for the assessment and AM elements of CAM. The feedback required to evaluate and adapt management experiments requires leading indicators, metrics that provide information about the drivers/ causal factors shaping future conditions and outcomes, rather than lagging indicators, which mainly provide information about past developments and effects. Leading indicators need to be defined on the basis of detailed change hypotheses showing how management actions are expected to lead to particular outcomes (Margoluis et al. 2013). Instead, CAM process goals commonly are stated in terms of a desired set of conditions within the managed biophysical system. A serious problem with a focus on biophysical indicators such as water flow targets is that social dynamics within the system may push the system irreversibly into an undesirable trajectory long before biophysical changes can be observed. Because change in human behavior is the primary driver of change in most social-ecological systems, change hypotheses and selected metrics need to account for social dynamics, and the most useful leading indicators are likely to involve monitoring the amount and nature of human behavior change. These change hypotheses are likely to have high levels of uncertainty, so indicators should be designed to test their validity as well as to track the project's progress.

Implementation challenges such as those described in this Special Feature should not just be thought of as inconveniences and barriers; they should instead become a major focus for research. As Berkley (2013) points out, the human/social systems associated with implementing CAM are much less understood than the natural systems. New and creative applications of the social sciences are needed for CAM to reach its potential as an approach to natural resource management in a complex and contentious world.

\section{ASSESSMENT OF THIS SPECIAL FEATURE}

This Special Feature was planned by the CAMNet Core Advisory Group as a means of identifying the usefulness of the journal format as a channel for practitioners to communicate useful information to other practitioners. My preliminary assessment of what we have learned from this exercise is that the concept of a CAM practitioners' journal has promise, but realization of that promise will require careful attention to the needs of and constraints on practitioners. The papers included in this Special
Feature present insights that could be of real value to CAM practitioners. However, the direct utility of this information is limited by the presentation format and writing style. It is highly likely that a manuscript tailored for an audience of academic researchers will not connect with an audience of practitioners, and vice versa. In this case, it is notable that the authors of the papers that most closely represented a practitioner's viewpoint experienced the most difficulty navigating through the Ecology and Society review process.

Papers aimed at practitioners need to directly connect theory to practice by providing guidelines for incorporating concepts into day-to-day activities. The papers in this Special Feature include much discussion of barriers to implementation of CAM, but relatively little practical guidance in how to overcome those barriers. In fact, a reasonable take-away point from this Special Feature is that the challenges of implementing CAM are beyond a practitioner's capacity to address. This relative lack of positive guidance does reflect a very real knowledge gap that applied researchers are working to fill, but the review process for journal articles is another contributing factor. Lessons learned through experience in particular situations may be of considerable value to practitioners working in similar settings as well as serving as the basis for future research. However, it is seldom possible to rigorously test those practical insights using data from the same case from which they were derived. Different evaluation criteria need to be applied if such information is to be included in journal articles.

Practitioners involved in CAM projects are best suited for identifying and describing information of value to other practitioners. Unfortunately, few practitioners have the time or motivation to write articles for publication in a peer-reviewed journal. Preparation and revision of such articles require a major investment of time, and time is a very scarce resource for most of us. Because research universities use the number of peer-reviewed publications as a primary criterion for promotion and retention, writing journal articles is considered an important part of the job for those with academic positions. In contrast, peer-reviewed publications generally are not required of CAM practitioners, so it is difficult for them to justify the time and other resources needed to write such articles. As a result, practitioners tend to have little training and practice in writing to satisfy the very specific argumentative and stylistic norms of peer review, which increases the time required for them to prepare a publishable article. Another unfortunate effect of these established norms is that relatively few practitioners routinely read many academic journals because peer-reviewed papers tend to be written by academic researchers for academic researchers, using jargon and phrasing that are readily understandable only to a small number of researchers in the same subfield. Additionally, theoretical constructs valued by academic reviewers commonly are viewed by practitioners as naïve, irrelevant, and impractical to implement in real-world efforts to address contentious natural resource issues. In short, a simple cost-benefit analysis convincingly argues against publication of peer-reviewed articles by practitioners.

There are ways to overcome these challenges. One approach that several journals in applied fields use to encourage practitioner submissions is establishing categories of articles with evaluation criteria designed to better meet practitioner needs and constraints. 
For example, the Journal of Agriculture, Food Systems and Community Development has established Case Studies and Reflective Essays as manuscript categories aimed at practitioners, targeting "material which might have a more popular journalistic style but also has much deeper substance than a trade journal article" (Agdevjournal.com, http://www.agdevjournal.com/typesof-submissions.html). This strategy not only reduces the time required for article preparation, but also encourages practitioners to read the journal, shifting the cost-benefit analysis toward publication by practitioners.

More generally, CAM research and practice both would benefit if it were routine to capture practitioners' experiential knowledge and derive generally useful lessons learned in CAM projects. Movement toward this new norm will require approaches and tools that make it quicker and easier for practitioners to participate. One approach would be to establish an experiential knowledge repository and to develop a set of questions and guidelines to simplify and structure practitioners' contributions. A complementary approach would be for someone who is both trained in ethnographic methods and knowledgeable about CAM to interview practitioners, eliciting practitioners' experiential knowledge in the form of stories and then deriving generally relevant lessons learned. CAMNet is well positioned to pilot and assess these and other approaches and tools.

\section{CONCLUSIONS}

The urgency and scale of the environmental and natural resource management problems we face underscore the importance of the topic of this Special Feature. The included papers collectively pose a number of questions that need to be addressed through ongoing conversations among researchers and practitioners:

- What is CAM supposed to accomplish? How can progress be measured, given real-world constraints? What would success look like in practice?

- Under what conditions is CAM feasible and worthwhile? Is there a particular scale (or range of scales) that is most suitable to such an approach? Many of the CAM processes described in this report are broad scale, with federal agencies as process conveners and/or central participants, and with a large number of stakeholders representing many different governance levels. Is collaboration possible when that many organizations are involved?

- How can a CAM process be initiated? In light of the common themes highlighted in this summary, this question might be better phrased thusly: How can the emergence of CAM be catalyzed? How can the process be designed to help stakeholders make the transition from dialogue to action?

- How can/should we deal with uncertainty in CAM? In most problem situations, managers do not have the luxury of time; some decisions have to be made immediately, without waiting for the results of experiments designed to reduce uncertainty.
- Finally, a set of questions particularly relevant to this Special Feature and to CAMNet are the following: How can we better foster two-way knowledge exchange between researchers and practitioners? What are appropriate venues and mechanisms for that exchange? It has always been assumed that practitioners learn from researchers; what can researchers learn from practitioners? How can we increase the usefulness and usability of the knowledge exchanged in both directions?

CAM offers a means by which communities can make sense of what is happening and why, so that community members can act in more thoughtful and informed ways. The challenges of implementing CAM are enormous, however. The best hope for addressing these challenges and realizing the potential of CAM is by broadening the conversation and forging links among the many different sources of knowledge and expertise. This Special Feature represents a step toward this goal.

Responses to this article can be read online at: http://www.ecologyandsociety.org/issues/responses. $\mathrm{php} / 6399$

\section{Acknowledgments:}

I would like to thank the editors of this Special Feature for encouraging me to write this paper. I am grateful to them and to Jennifer Pratt Miles for sharing their good ideas and sound advice, and to the reviewers for their very helpful feedback. I would also like to thank Herman Karl for getting me involved with CAMNet and for insights shared and encouragement given over many years.

\section{LITERATURE CITED}

Andrews, C. J. 2002. Humble analysis: the practice of joint factfinding. Praeger, Westport, Connecticut, USA.

Beierle, T. C., and D. M. Konisky. 2000, Values, conflict, and trust in participatory environmental planning. Journal of Policy Analysis and Management 19(4):587-602.

Benson, M. H., and A. B. Stone. 2013. Practitioner perceptions of adaptive management implementation in the United States. Ecology and Society 18(3): 32. http://dx.doi.org/10.5751/ ES-05613-180332

Beratan, K. K. 2007. A cognition-based view of decision processes in complex social-ecological systems. Ecology and Society 12(1): 27. [online] URL: http://www.ecologyandsociety.org/vol12/iss1/ $\underline{\operatorname{art} 27}$

Beratan, K. K., and H. A. Karl. 2012. Managing the sciencepolicy interface in a complex and contentious world. Pages 183-216 in H. A. Karl, L. Scarlett, J. C. Vargas-Moreno, and M. Flaxman, editors. Restoring lands-coordinating science, politics and action. Springer, New York, New York, USA. http://dx.doi. org/10.1007/978-94-007-2549-2_10

Berkley, J. 2013. Opportunities for collaborative adaptive management progress: integrating stakeholder assessments into 
progress measurement. Ecology and Society 18(4): 69. http://dx. doi.org/10.5751/ES-05988-180469

Carlsson, L., and F. Berkes. 2005. Co-management: concepts and methodological implications. Journal of Environmental Management 75(1):65-76 http://dx.doi.org/10.1016/j.jenvman.2004.11.008

Caves, J. K., G. S. Bodner, K. Simms, L. A. Fisher, and T. Robertson. 2013. Integrating collaboration, adaptive management, and scenario-planning: experiences at Las Cienegas National Conservation Area. Ecology and Society 18(3): 43. http://dx.doi. org/10.5751/ES-05749-180343

Childs, C., A. M. York, D. White, M. L. Schoon, and G. S. Bodner. 2013. Navigating a murky adaptive comanagement governance network: Agua Fria Watershed, Arizona, USA. Ecology and Society 18(4): 11. http://dx.doi.org/10.5751/ES-05636-180411

Conley, A., and M. A. Moote. 2003. Evaluating collaborative natural resource management. Society \& Natural Resources: An International Journal 16(5):371-386. http://dx.doi.

org/10.1080/08941920309181

Crona, B., and K. Hubacek. 2010. The right connections: how do social networks lubricate the machinery of natural resource governance? Ecology and Society 15(4): 18. [online] URL: http:// www.ecologyandsociety.org/vol15/iss4/art18/

Curtin, C. 2014. Resilience design: toward a synthesis of cognition, learning, and collaboration for adaptive problem solving in conservation and natural resource stewardship. Ecology and Society, in press 19(2).

Davidson-Hunt, I. J., and F. Berkes. 2002. Nature and society through the lens of resilience: toward a human-in-ecosystem perspective. Pages 53-82 in F. Berkes, J. Colding, and C. Folke, editors. Navigating social-ecological systems: building resilience for complexity and change. Cambridge University Press, Cambridge, UK. http://dx.doi.org/10.1017/CBO9780511541957.006

Galat, D. L., and J. Berkley, 2014. Introduction to exploring opportunities for advancing collaborative adaptive management (CAM): integrating experience and practice. Ecology and Society, in press $19(2)$.

Green, O. O., B. A. Cosens, and A. S. Garmestani. 2013. Resilience in transboundary water governance: the Okavango River Basin. Ecology and Society 18(2): 23. http://dx.doi.org/10.5751/ ES-05453-180223

Greig, L. A., D. R. Marmorek, C. Murray, and D. C. E. Robinson. 2013. Insight into enabling adaptive management. Ecology and Society 18(3): 24. http://dx.doi.org/10.5751/ES-05686-18032

Gunderson, L. 1999. Resilience, flexibility and adaptive management-antidotes for spurious certitude? Conservation Ecology 3(1): 7. [online] URL: http://www.ecologyandsociety.org/ vol3/iss1/art7l.

Himmelman, A. T. 1996. On the theory and practice of transformational collaboration: from social service to social justice. Pages 19-43 in C. Huxham, editor. Creating collaborative advantage. SAGE, London, UK. http://dx.doi.org/10.4135/9781446221600. $\underline{\mathrm{n} 2}$
Holling, C. S., S. R. Carpenter, W. A. Brock, and L. H. Gunderson. 2002. Discoveries for sustainable futures. Pages 395-418 in L. H. Gunderson and C. S. Holling, editors. Panarchy: understanding transformations in human and natural systems. Island Press, Washington, D.C., USA.

Imperial, M., and T. Hennessey. 2000. Improving watershed governance: collaboration, public value, and accountability. Paper presented at the American Political Science Association 96th annual meeting. Washington, D.C., September. http://www. academia.edu/718573/Improving watershed governance Collaboration public value and accountability

Jackson, P. M., and L. Stainsby. 2000. The public manager in 2010: managing public sector networked organizations. Public Money \& Management 20(1):11-16. http://dx.doi. org/10.1111/1467-9302.00196

Laws, D., D. Hogendoorn, and H. Karl. 2014. Hot adaptation: what conflict can contribute to collaborative natural resource management. Ecology and Society, in press 19(2).

Loftin, M. K. 2014. Truths and governance for adaptive management. Ecology and Society, in press 19(2).

LoSchiavo, A. J., R. G. Best, R. E. Burns, S. Gray, M. C. Harwell, E. B. Hines, A. R. McLean, T. St. Clair, S. Traxler, and J. W. Vearil. 2013. Lessons learned from the first decade of adaptive management in comprehensive Everglades restoration. Ecology and Society 18(4): 70. http://dx.doi.org/10.5751/ES-06065-180470

Margoluis, R., C. Stem, V. Swaminathan, M. Brown, A. Johnson, G. Placci, N. Salafsky, and I. Tilders. 2013. Results chains: a tool for conservation action design, management, and evaluation. Ecology and Society 18(3): 22. http://dx.doi.org/10.5751/ ES-05610-180322

Monroe, M. C., R. Plate, and A. Oxarart. 2013. Intermediate collaborative adaptive management strategies build stakeholder capacity. Ecology and Society 18(2): 24. http://dx.doi.org/10.5751/ ES-05444-180224

Pratt Miles, J. D. 2013. Designing collaborative processes for adaptive management: four structures for multistakeholder collaboration. Ecology and Society 18(4): 5. http://dx.doi. org/10.5751/ES-05709-180405

Rittel, H. W., and M. M. Webber. 1973. Dilemmas in general planning theory. Policy Sciences 4(2):155-169. http://dx.doi. org/10.1007/BF01405730

Scarlett, L. 2013. Collaborative adaptive management: challenges and opportunities. Ecology and Society 18(3): 26. http://dx.doi. org/10.5751/ES-05762-180326

Smedstad, J. A., and H. Gosnell. 2013. Do adaptive comanagement processes lead to adaptive comanagement outcomes? A multicase study of long-term outcomes associated with the National Riparian Service Team's place-based riparian assistance. Ecology and Society 18(4): 8 . http://dx.doi. org/10.5751/ES-05793-180408 